\title{
Evaluation of effect of insertion of casing by rotation on existing piles
}

\section{Shinya Inazumi}

Professor, Department of Civil Engineering, Shibaura Institute

of Technology, Tokyo, Japan (Orcid:0000-0002-5639-5254)

(corresponding author: inazumi@shibaura-it.ac.jp)

Shigeaki Tanaka

President, Ibuki Industry Co. Ltd, Osaka, Japan

\section{Takahiro Komaki}

Technical Sales Director, Toyo Industry Co. Ltd, Fukuoka, Japan

Shuichi Kuwahara

President, Marushin Co. Ltd, Tokyo, Japan

Various issues have been encountered in the removal work of existing piles, such as existing piles being left in the ground, the subsidence of the surrounding ground and the deterioration of the ground environment when reusing the site. However, there are no regulations for the filling material to be injected into the draw holes that form after the removal of existing piles or for the removal work itself. In this study, therefore, in order to evaluate the effect of the insertion by rotation of the casing onto an existing pile as part of the work to remove existing piles, the effect of the stress loaded onto an existing pile when the casing is inserted into the ground using moving-particle semi-implicit-computer-aided engineering and the mechanism of its occurrence are clarified. As a result, it is found that the inner diameter of the casing used, the value of the plastic viscosity of the drilling fluid and the mechanism by which the stress is loaded onto an existing pile can be evaluated such that the destruction of the existing piles can be avoided.

\section{Notation}

D outer diameter

$d \quad$ distance to loaded stress

$d \quad$ inner diameter

F magnitude of loaded stress

g gravity vector

$I_{\mathrm{p}} \quad$ second polar moment of area

$\boldsymbol{n} \quad$ unit vector in the direction perpendicular to the surface

$P \quad$ pressure

$R \quad$ square of the distance to a certain small area

$T$ torsional moment (torque)

$\boldsymbol{u} \quad$ velocity vector

$v \quad$ kinematic viscosity coefficient

$\delta$ delta function for surface tension acting on the surface

$\kappa \quad$ curvature

$\rho$ density of the fluid

$\sigma \quad$ surface tension coefficient

$\tau_{\max }$ maximum torsional stress

$\tau \quad$ torsional stress

\section{Introduction}

In recent years, the deterioration of architectural and civil engineering structures constructed during the period of high economic growth, from 1954 to 1970 , has progressed remarkably in Japan. This has become a serious issue for the construction industry. Moreover, due to the Great East Japan earthquake of 2011 and considering the earthquakes that are expected to occur in the future directly under the Tokyo metropolitan area and in the Nankai Trough, disaster prevention awareness among the general public will continue to increase. Furthermore, the number of users of architectural and civil engineering structures will continue to decrease due to the declining population and the changing needs of the times. As a result, the number of projects related to the dismantling and rebuilding of structures has been increasing.

Most cities in Japan and South-east Asia are located on soft ground; thus, the construction methods chosen for most structures involve the use of pile foundations. Therefore, when dismantling and removing existing structures, the piles existing in the ground must be securely removed so that they will not interfere with the newly built pile foundations and/or the retaining walls of the new structures, and the draw holes that form after their removal must be properly filled. If this is not done, the presence of these existing piles will adversely affect the construction period and the quality of the newly installed piles, such as the placing and retaining work (see Figure 1). The existing piles that remain after the dismantling and removal of existing structures are treated as industrial waste unless their utility is recognised, and the existence of these piles often causes complications in land sale transactions.

One of the reasons why existing piles remain in the ground is that it is not easy to remove the piles completely because they may break during the process of pulling them out, as shown in Figure 2 (Inazumi et al., 2017; Kuwahara and Inazumi, 2019). Pile removal work generally involves a tubular machine, called a 'casing', used to drill holes around existing piles. During the drilling work, the deposits around an existing pile and the drilling fluid rotate together with the casing, but the existing pile does not rotate because it is fixed to the supporting layer (see Figure 3) (Kuwahara et al., 2019). As a result, torsional stress is loaded onto the existing pile. The pile may break due to the large torsional stress. However, this theory is based on the experience of engineers, and it is not known at present how much torsional stress is actually loaded onto a pile or how much stress is required to break an existing pile. In addition, a great 


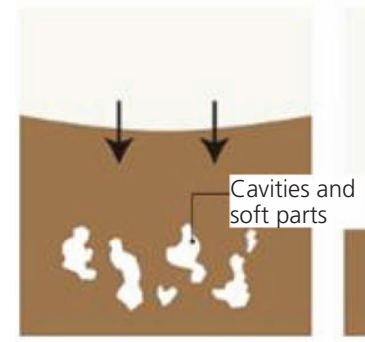

Subsidence of
surrounding ground

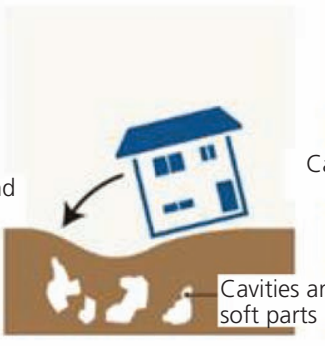

Slope/collapse of adjacent structure

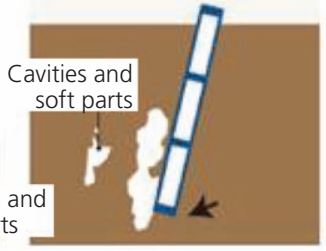

Slope of newly built pile driving

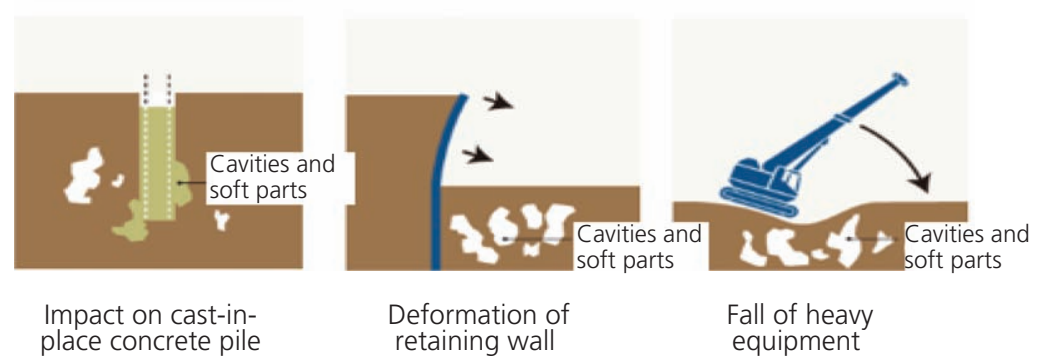

Figure 1. Cases of negative impact on ground due to defects in removal of existing piles

deal of time is needed to conduct an on-site survey (Kuwahara et al., 2019).

In this study, therefore, a moving-particle semi-implicit-computeraided engineering (MPS-CAE) analysis is performed to evaluate the mechanism of the stress loaded onto an existing pile when a steel casing is inserted into the ground. More specifically, to verify the mechanism of stress generation, there are three points of view: $(a)$ when the type of existing pile is changed, $(b)$ when the viscosity of the drilling fluid between the existing pile and the casing is changed and $(c)$ when the interval width between the casing and the existing pile is changed.

\section{Outline of removal methods for existing piles}

Current status of existing piles

The main types of existing piles are concrete piles and steel pipe (SP) piles. In addition, the methods usually adopted for

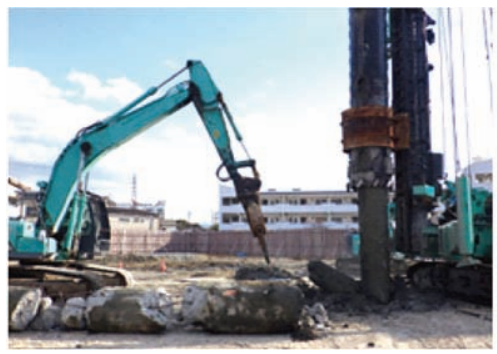

(a)

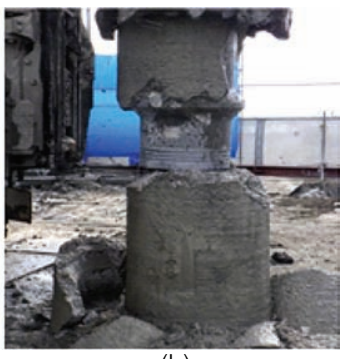

(b)
Figure 2. Existing pile that broke in the process of removing it: (a) full view of removal work; (b) state of broken existing pile driving the piles are hammering and rotary embedding (Inazumi et al., 2020a, 2021; Kuwahara et al., 2020). When an existing pile is removed, it is often under an undesirable condition, as shown in Figure 4, such as the arrangement of the existing piles is different from the drawing, the existing piles are not even, an existing pile has broken in the ground, the joint sections of an existing pile are bad and an existing pile was unexpectedly placed at an incline. In the future, it will become

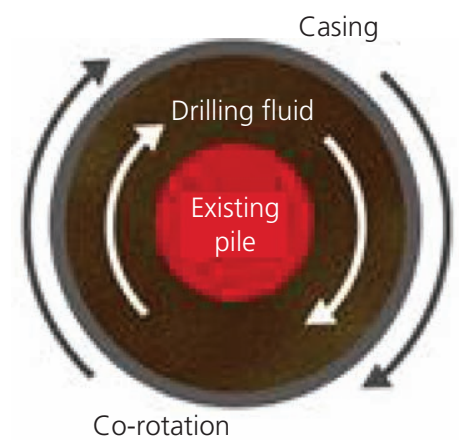

Insertion with rotation

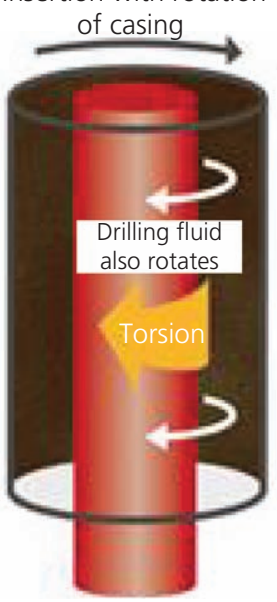

Existing pile does not rotate

Figure 3. Assumed mechanism of torsional stress loaded onto an existing pile 


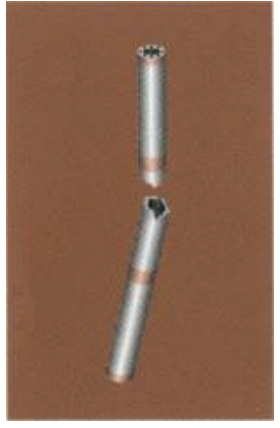

(a)

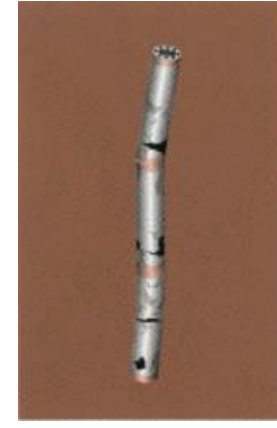

(b)

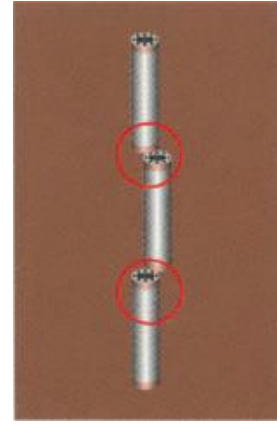

(c)

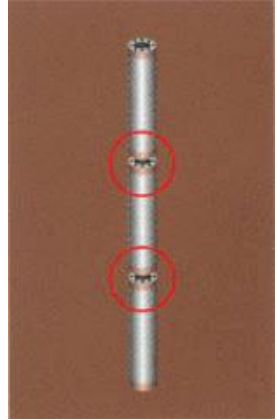

(d)

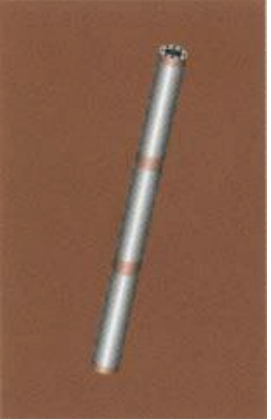

(e)

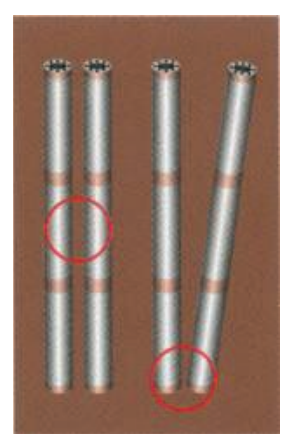

(f)

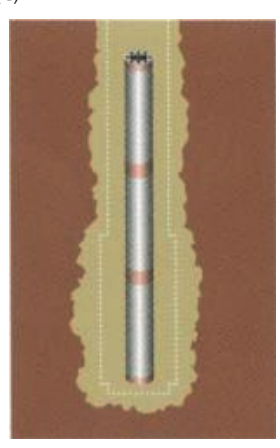

(g)

Figure 4. Buried status of an existing pile: (a) snapped; (b) broken; (c) joint offset; (d) joint unbonded; (e) oblique pile; (f) pile spacing is narrow; (g) hypertrophy of cement milk

more and more necessary to remove existing piles buried under various conditions safely and securely.

\section{Methods for removal of existing piles}

The construction procedure using a wire rope, which among all others is a general method for removing existing piles, is shown in Figure 5 and described in the following (Kuwahara et al., 2019).

(a) The steel casing is set so that the centre of the casing is aligned with the core of the existing pile.

(b) While discharging the drilling fluid (water or bentonite water), the casing is inserted by rotation.

(c) After completing the insertion of the casing by rotation down to the specified depth, the casing is pulled up, a wire rope is inserted into the tip of the casing and the rope attached to the tip of the casing is set in the existing pile.

(d) The filling material is injected into the draw hole while the existing pile is being pulled up. (If the existing pile is heavy, it should be lifted with multiple heavy equipment and the top of the pile is cut off to decrease the weight.)

However, this removal method has some shortcomings, as shown in Figure 6. Firstly, when piles are buried under the undesirable conditions shown in Figure 4, it is difficult to remove them reliably with this method. Next, when injecting the filling material into a draw hole, it is not possible to fill in the very deepest part of the hole because the filling material is injected from the surface of the ground, and thus, voids form easily in the ground. Finally, when pulling up the pile, the wire is pulled up vertically, so there is a risk that the wire will not be able to withstand the stress or that the pile may break in the middle.

As a removal method devised to overcome the aforementioned issues that are sometimes encountered with the general removal method, there is a removal method in which the tip of the pile is chucked and pulled out. The construction procedure for this method is shown in Figure 7 and described in the following (Kuwahara et al., 2019; Inazumi et al., 2020b, 2020c).

(a) Using a backhoe, the ground is excavated until the top end of the existing pile is exposed.

(b) The steel casing is set so as to enclose the top end of the existing pile.

(c) The ground is excavated by the rotating casing, and the drilling fluid is discharged from the tip of the casing.

(d) The chuck claws are projected inwards from the casing at the lower end of the existing pile.

(e) With the existing pile enclosed by the casing, the pile is pulled up while the casing is rotating and the filling material is being injected from the tip of the casing.

In this removal method, because the entire length of the existing pile is pulled up in the state of being enclosed by the casing, it is 

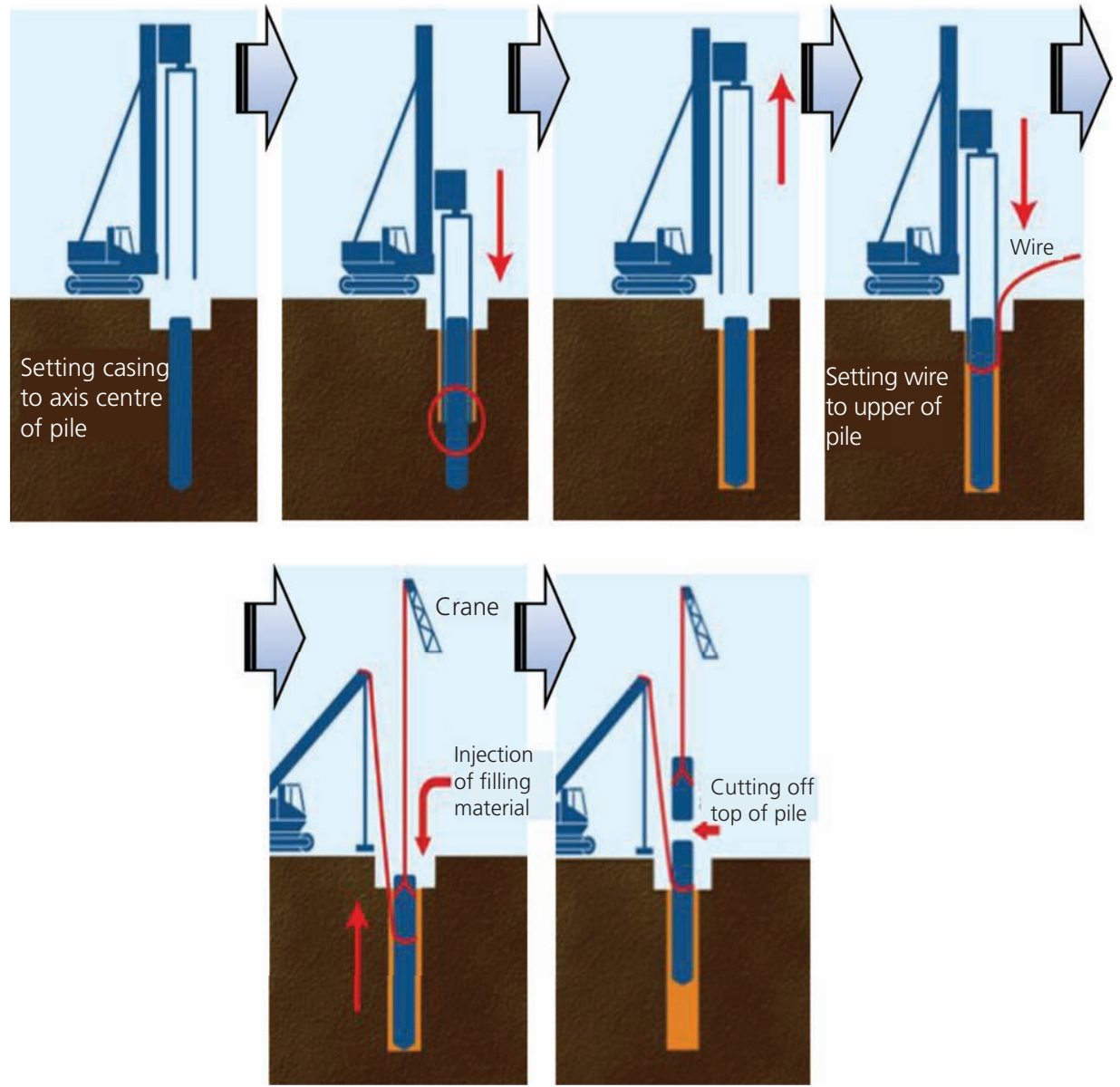

Figure 5. Construction procedure for the method of removing an existing pile using a wire rope

possible to pull out the existing pile reliably even under undesirable conditions. Moreover, because no wire rope is used, there is no risk of the existing pile being dropped or the heavy machinery overturning due to breakage. (a)

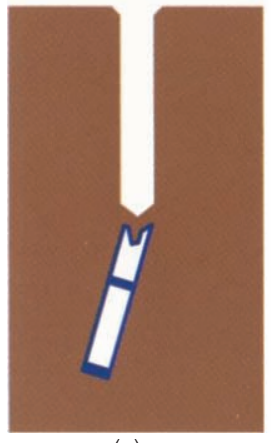

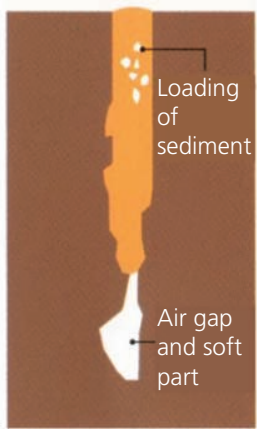

(b)

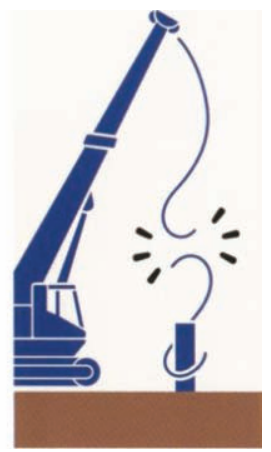

(c)
Figure 6. Problems with the method of removing an existing pile using a wire rope: (a) leaving the broken pile underground; (b) incomplete injection; (c) sling rail wire breaks
Torsion of an existing pile due to insertion of the casing by rotation in methods for removal of existing piles

It is thought that existing piles may break because the drilling fluid in the casing is circulated by the insertion of the casing by rotation and the torsional stress is loaded onto the existing piles (see Figure 3). In principle, when drilling with a casing in a removal method that uses a wire or chucking and the casing does not reach the tip of the existing pile, the existing pile does not separate from the ground but remains fixed to the supporting layers. In other words, the existing pile itself does not rotate. Only the drilling fluid rotates, such that torsional stress is loaded onto the existing pile. As the casing is gradually inserted by rotation, the stress generated by the insertion of the rotating casing in the pile direction is loaded through the drilling fluid. At the same time, the circulating volume of the drilling fluid with the casing increases, so the stress loaded onto the existing pile increases. It is thought that an existing pile will often not be able to withstand the stress and will break.

\section{CAE with MPS method}

Computer-aided engineering

CAE is an alternative technology for large-scale experiments, conducted in a room or in situ, using prototypes that have been 


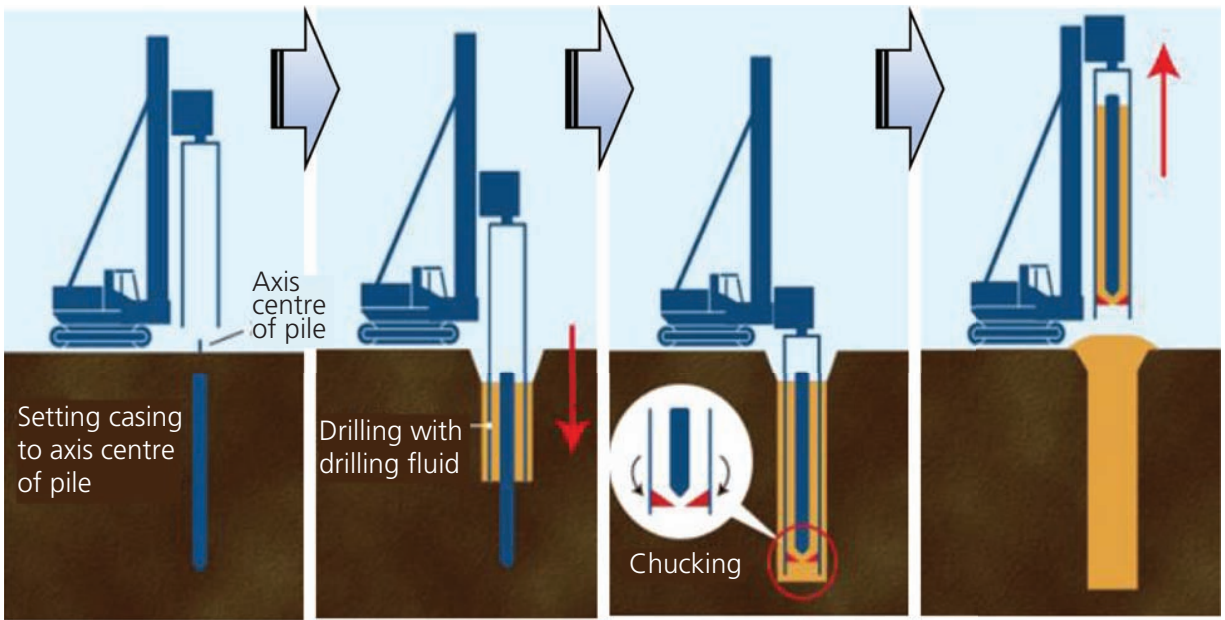

Figure 7. Construction procedure for the removal method by chucking the tip of the existing pile

created in a study as part of a development process of 'manufacturing'. In other words, 'CAE' is a general term for technology that simulates and analyses prototypes on a computer formed by computer-aided design (CAD) and so on, considering the site conditions (Chang, 2014; Inazumi et al., 2020c; Pan et al., 2016). At the same time, CAE may refer to computer-aided engineering work or its tools for prior examination, design, manufacturing and process design of construction methods and products. In the field of geotechnical engineering, CAE can be used to visualise the inside of the ground and the stress loaded on the inside of the ground and to understand experiments that would normally require huge costs and/or phenomena that would be difficult to reproduce. In addition, by performing appropriate postprocessing, it is possible to communicate with other people in a visually easy-to-understand manner.

\section{Particle method and MPS method}

With the remarkable development of computer technology in recent years, a method of analysis called the particle method (PM) has been developed. Here, the finite-element method (FEM) and the difference method (DM) comprise the grid method, in which the space is divided into grids and a physical quantity is assigned to each grid as a variable for calculation (Yang et al., 2020). Unlike the FEM and DM, the PM does not use grids, but instead discretises the continuum as particles that move with each physical quantity at each calculation point in a Lagrangian manner. Thus far, Inazumi et al. (2018) used the distinct-element method (DEM) to calculate the amount of movement of each particle by expressing the interacting stress between particles using the spring constant, damping constant, friction coefficient and so on. The DEM was also applied to the reproduction and performance evaluation of removal methods for existing piles (Inazumi et al., 2018). In this study, the authors apply the MPS method (Hattori, 2015; Shakibaeini and Jin, 2012; Tanaka et al., 2018) to analyse the behaviour of fluid particles according to the equation of motion for fluids. The governing equations for the incompressible flow used in the analysis are the mass conservation law, Equation 1, and the momentum conservation law, Equation 2, considering surface tension.

1. $\frac{D \rho}{D t}=0$

2. $\frac{D u}{D t}=-\frac{1}{\rho} \nabla P+v \nabla^{2} \boldsymbol{u}+\boldsymbol{g}+\frac{1}{\rho} \sigma \kappa \delta \boldsymbol{n}$

where $\rho$ is the density of the fluid, $\boldsymbol{u}$ is the velocity vector, $P$ is the pressure, $v$ is the kinematic viscosity coefficient, $g$ is the gravity vector, $\sigma$ is the surface tension coefficient, $\kappa$ is the curvature, $\delta$ is the delta function for the surface tension acting on the surface and $\boldsymbol{n}$ is the unit vector in the direction perpendicular to the surface.

In the MPS method, each differential operator (slope, divergence and Laplacian) of the governing equation, shown in Equation 2, is discretised by a weighting function (Hattori, 2015; Shakibaeini and Jin, 2012; Tanaka et al., 2018). The weighting function depends on the interparticle distance and the influence radius (2.1-4.1 times the interparticle distance) in each particle interaction model.

In this study, therefore, an MPS-CAE analysis is performed to evaluate the mechanism of the stress loaded onto an existing pile when the steel casing is inserted into the ground.

\section{Setting target in MPS-CAE analysis}

Setting parameters

Drilling fluid

The drilling fluid to be analysed in this study was assumed to be a Bingham fluid, so it was necessary to set the corresponding parameters. In terms of the density and the yield value of the 
Table 1. Material parameters for the drilling fluid used in MPS-CAE analysis

\begin{tabular}{lccccc|} 
& Density: $\mathbf{k g} / \mathbf{m}^{\mathbf{3}}$ & Plastic viscosity: Pa s & Yield value: Pa & Flow limit strain: $\mathbf{1 / s}$ & Contact angle: ${ }^{\circ}$ \\
\hline Drilling fluid & 1200 & 1 & 10 & $1.00 \times 10^{4}$ & 50 \\
Drilling fluid & 1200 & 100 & 10 & $1.00 \times 10^{4}$ & 50 \\
Drilling fluid & 1200 & 1000 & 10 & $1.00 \times 10^{4}$ & 50
\end{tabular}

drilling fluid, the parameter values for the critical strain ratio of the flow of the drilling fluid and the contact angle between the drilling fluid and the casing were determined from the papers by Inazumi et al. (2020b, 2020c). Regarding the plastic viscosity of the drilling fluid, the value of small viscosity was adopted, as shown in the papers by Inazumi et al. (2020b, 2020c), and the parameters for medium viscosity and large viscosity were assumed based on the value of small viscosity. The parameters for the drilling fluid used in the MPS-CAE analysis are summarised in Table 1 .

\section{Casing}

The material for the casing was assumed to be steel in this study, and thus it was necessary to set the material parameters and velocities for the insertion of the casing by rotation before executing the MPS-CAE analysis. The material parameters for steel were assumed by referring to the publications by Inazumi et al. (2020c), Nakamura and Nakamura (2000) and Rahman and Chilingarian (1995). The values for the velocities of the insertion of the casing by rotation were adopted from the paper by Inazumi et al. (2020c). The material parameters for the casing and the velocities of the insertion of the casing by rotation are shown in Table 2 .

\section{Existing piles}

The shapes of the existing piles and the casing were simplified and created using three-dimensional CAD in this study. For the existing piles, two types of prefabricated concrete (PC) piles and two types of SP piles with different pile diameters were created. The pile diameter of the first type of PC pile was set to $0.6 \mathrm{~m}$, which is the same size as that of the pulled-out existing piles at the on-site location reported by Inazumi et al. (2020c), while the pile diameter of the second type of PC pile was set at $0.3 \mathrm{~m}-$ namely, half the size of the first type. The SP piles had shapes regulated by a Japanese Industrial Standard (JIS) (JIS A 5525) (JSA, 2019) - that is, the nominal diameters of the SP pile were assumed to be 0.6 and $0.3 \mathrm{~m}$. The lengths of the PC piles and the SP piles were all assumed to be $16 \mathrm{~m}$ regardless of the difference in pile diameter. Based on the removal method and the cylindrical

Table 2. Material parameters and velocities of insertion of casing by rotation used in MPS-CAE analysis

\begin{tabular}{|c|c|c|c|c|}
\hline & $\begin{array}{l}\text { Young's } \\
\text { modulus: } \\
\mathrm{N} / \mathrm{mm}^{2}\end{array}$ & $\begin{array}{l}\text { Poisson's } \\
\text { ratio }\end{array}$ & $\begin{array}{l}\text { Rotational } \\
\text { velocity: } \\
\text { rpm }\end{array}$ & $\begin{array}{c}\text { Insertion } \\
\text { velocity: } \\
\text { m/min }\end{array}$ \\
\hline Casing & $2.05 \times 10^{5}$ & 0 & 15 & 0.50 \\
\hline
\end{tabular}

rpm, revolutions per min casing used at a certain on-site location, the diameters of the casing were assumed such that the interval widths between the casing and the existing piles were 0.1 and $0.3 \mathrm{~m}$. Table 3 shows the specifications of the PC piles, the SP piles and the casings assumed in the MPS-CAE analysis.

\section{Setting cross-section}

In the on-site removal work of existing piles, the space enclosed inside the casing and its surroundings are filled with drilling fluid because the casing is inserted by rotation while discharging drilling fluid from the tip of the casing. However, it is difficult to reproduce drilling holes with the MPS-CAE analysis while discharging drilling fluid from the tip of the casing, so the MPS-CAE analysis was performed from the state of being previously filled with drilling fluid. If the pile length of $16 \mathrm{~m}$ is filled with particles (calculation points), assumed as the drilling fluid, the number of particles will increase and the MPS-CAE analysis will take a long time. At least the existing pile length of $0.5-0.6 \mathrm{~m}$ should be filled with drilling fluid particles in the MPS-CAE analysis. Therefore, MPS-CAE was carried out as shown in Figures 8 and 9 in which the casing was inserted by rotation at a velocity of $0.5 \mathrm{~m} / \mathrm{min}$ for $1 \mathrm{~min}$ in two cases: first, the case of the interval width between the casing and the existing pile being $0.1 \mathrm{~m}$ (i.e. when the interval space was filled with 8480 particles) and second, the case of the interval width between the casing and the existing pile being $0.3 \mathrm{~m}$ (i.e. when the interval space was filled with 36000 particles). The particle size of the drilling fluid was set to $0.03 \mathrm{~m}$. Regarding the distance of $0.03 \mathrm{~m}$ between particles, three particles were able to pass even when the interval width between the casing and the existing pile was $0.1 \mathrm{~m}$, which was the smallest width.

The authors evaluated the effect of the insertion of the casing in the ground by rotation on the existing piles from the three viewpoints of the stress loaded onto the existing piles, the rate of

Table 3. Various sizes of existing piles and casings used in MPSCAE analysis

\begin{tabular}{|ccccc|}
\hline & $\begin{array}{c}\text { Length: } \\
\mathbf{m}\end{array}$ & $\begin{array}{c}\text { Outer } \\
\text { diameter: } \mathbf{m}\end{array}$ & $\begin{array}{c}\text { Inner } \\
\text { diameter: } \\
\mathbf{m}\end{array}$ & $\begin{array}{c}\text { Nominal } \\
\text { diameter: } \mathbf{m}\end{array}$ \\
\hline Existing & 16.0 & 0.60 & - & 0.6 \\
PC pile & & 0.30 & - & 0.3 \\
& & & & \\
Existing & 16.0 & 0.60 & 0.58 & 0.6 \\
SP pile & & 0.32 & 0.30 & 0.3 \\
& & & & - \\
Casing & 18.2 & 0.88 & 0.80 & - \\
& & 1.28 & 1.20 & -
\end{tabular}


Evaluation of effect of insertion of casing

by rotation on existing piles

Inazumi, Tanaka, Komaki and Kuwahara

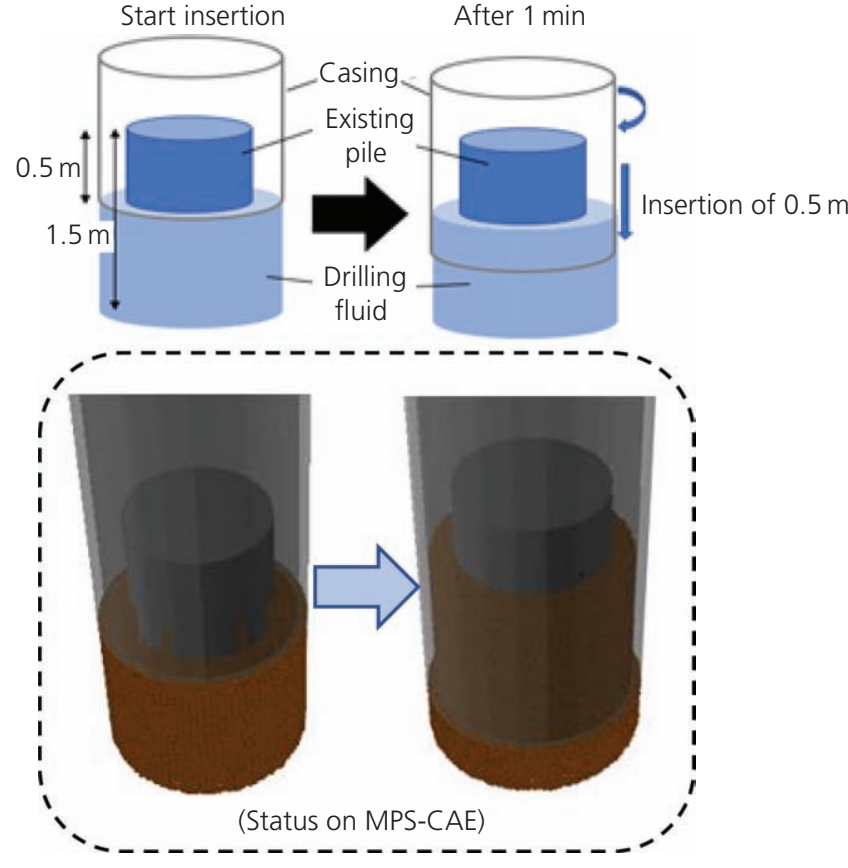

Figure 8. Overview of setting target in MPS-CAE analysis

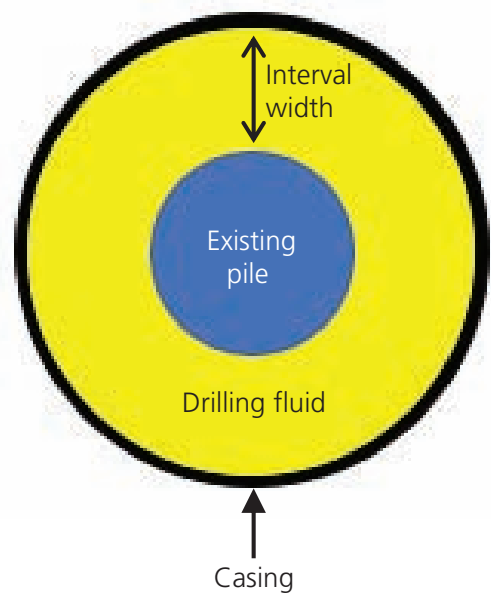

Figure 9. Top view of setting target in MPS-CAE analysis

stress propagating from the casing to the existing piles and the safety factor against the breakage of the existing piles.

Estimation method for stress loaded onto an existing pile in MPS-CAE analysis

In the calculation of the stress loaded onto an existing pile, it is assumed in the MPS-CAE analysis that $0.5 \mathrm{~m}$ of the pile head is exposed from the surface of the ground, as shown in Figure 10, and that the casing is inserted by rotation for $1 \mathrm{~min}$. Therefore, the position of the stress loaded onto an existing pile is $1.0 \mathrm{~m}$ from the existing pile head.

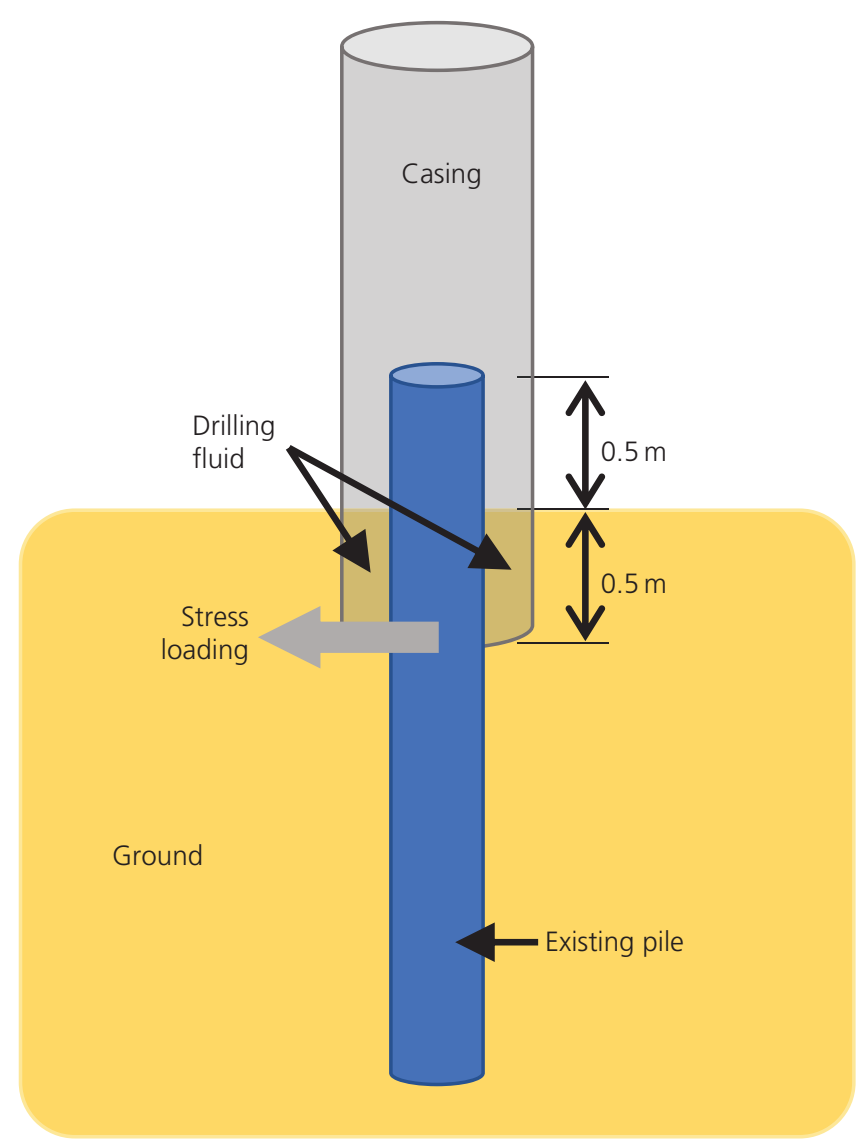

Figure 10. Assumptions in estimation of the stress loaded onto an existing pile in MPS-CAE analysis

The stress loaded onto an existing pile $(F)$ is obtained by adding the pressure term, the viscosity term, the surface tension term and the external force term and calculating them as the sum of the neighbouring particles, as indicated in the following equation:

3. $\vec{F}=-\sum_{i} m_{i}\left(-\frac{1}{\rho} \nabla P_{i}+\mu \nabla^{2} \vec{u}_{i}+\nabla \varnothing_{i}+\overrightarrow{\alpha_{\epsilon x t, i}}\right)$

In the case of torsion, the torsional moment is called torque $(T)$. It is expressed as the following equation:

4. $T=\frac{F d}{2}$

where $F$ is the magnitude of the loaded stress and $d$ is the distance to the loaded stress.

In the case of an existing PC pile, the second polar moment of the area $\left(I_{\mathrm{p}}\right)$ is obtained by multiplying the square of the distance to a certain small area $(r)$ by the area of the small area and differentiating it over the entire cross-section (see the following equation). 
Evaluation of effect of insertion of casing

by rotation on existing piles

Inazumi, Tanaka, Komaki and Kuwahara

$$
I_{\mathrm{p}}=\int_{0}^{d / 2} r^{2}(2 \pi r \mathrm{~d} r)=2 \pi \int_{0}^{d / 2} r^{3} \mathrm{~d} r=2 \pi\left[\frac{r^{4}}{4}\right]_{0}^{d / 2}=\frac{\pi d^{4}}{32}
$$

In the case of an existing SP pile, $d$ is represented as $D^{4}-d^{4}$, and therefore, the following equation is obtained:

6. $I_{\mathrm{p}}=\frac{\pi}{32}\left(D^{4}-d^{4}\right)$

where $D$ is the outer diameter and $d$ is the inner diameter.

Using Equations 3-6, the torsional stress $(\tau)$ and the maximum torsional stress $\left(\tau_{\max }\right)$ are given by the following equations:

7. PC pile: $\tau=\frac{T d}{I_{\mathrm{p}}} \quad \tau_{\max }=\frac{T d}{2 I_{\mathrm{p}}}$

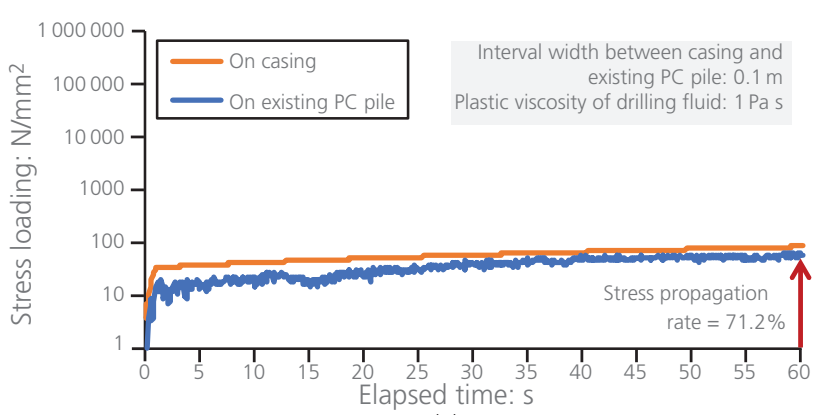

(a)

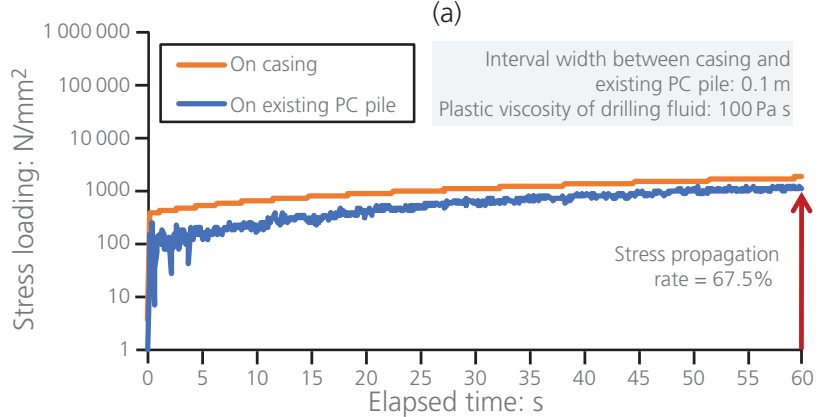

(b)

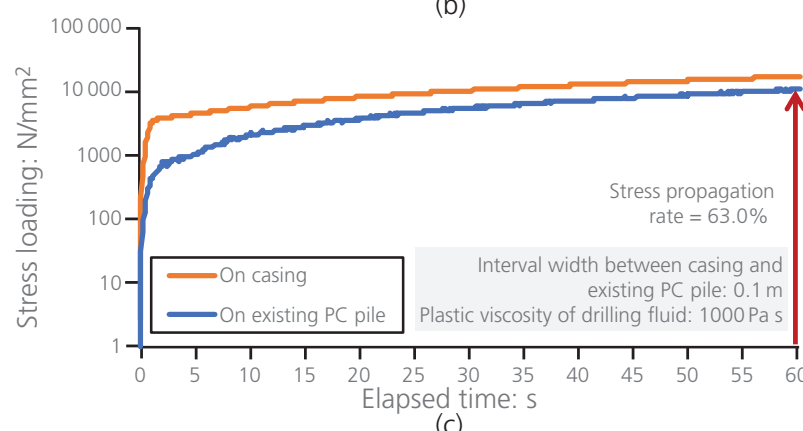

8. SP pile: $\quad \tau=\frac{T D}{I_{\mathrm{p}}} \quad \tau_{\max }=\frac{T D}{2 I_{\mathrm{p}}}$

It is confirmed whether the allowable shear stress of an existing pile can resist the torsional stress generated by the insertion of the casing in the ground by rotation (Nishino, 1987; Nixon and McRoberts, 1976). In this study, the allowable shear stress value is assumed as $0.875 \mathrm{~N} / \mathrm{mm}^{2}$ for existing PC piles and as $90.45 \mathrm{~N} / \mathrm{mm}^{2}$ for existing SP piles, referring to the publications by Nishino (1987) and Nixon and McRoberts (1976).

\section{Impact on existing piles due to insertion of the casing by rotation}

Rate of stress propagation from the casing to existing piles

Figures 11 and 12 present the phenomenon of the stress loaded onto existing PC piles and existing SP piles, respectively, with a pile diameter of $0.6 \mathrm{~m}$ when the casing is inserted by rotation for

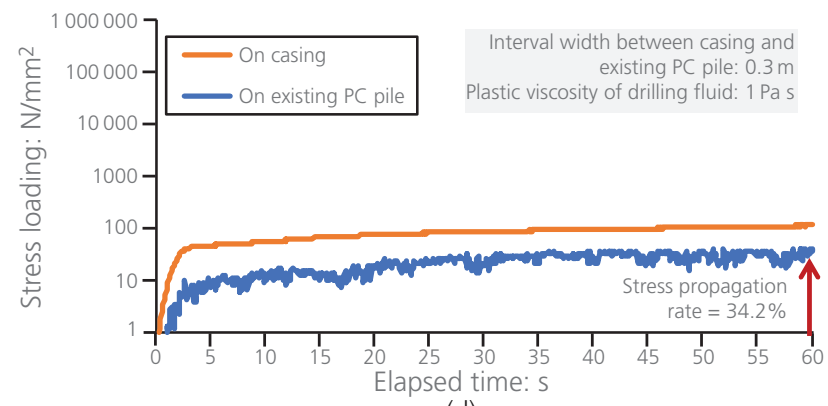

(d)

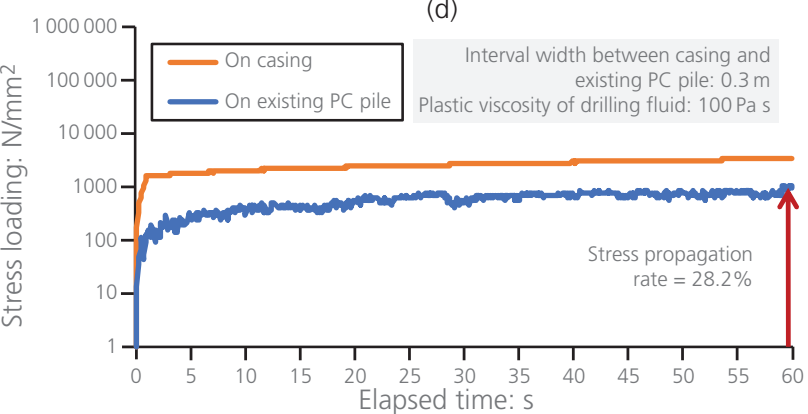

(e)

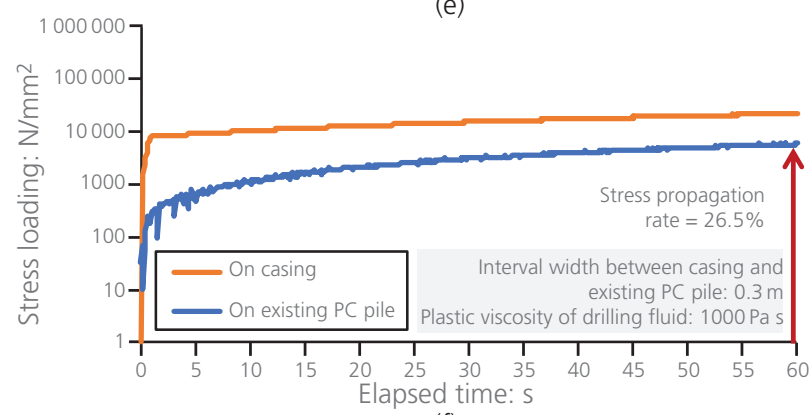

(f)

Figure 11. Stress loaded onto an existing PC pile when the casing is inserted by rotation: (a) Case_PC_0.6_0.1_1;

(b) Case_PC_0.6_0.1_100; (c) Case_PC_0.6_0.1_1000; (d) Case_PC_0.6_0.3_1; (e) Case_PC_0.6_0.3_100; (f) Case_PC_0.6_0.3_1000 


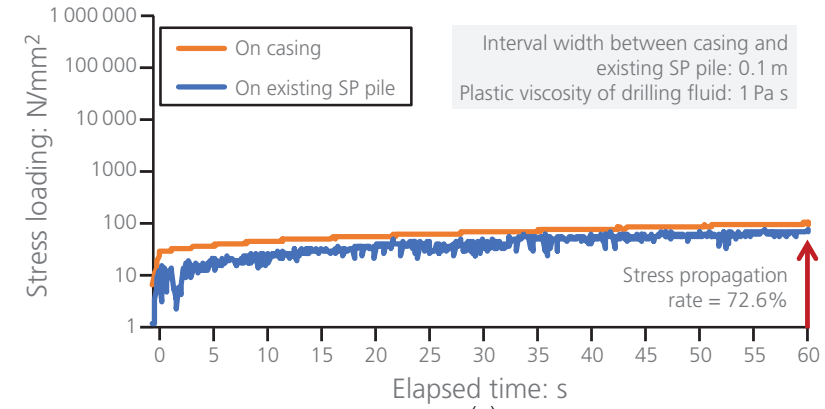

(a)

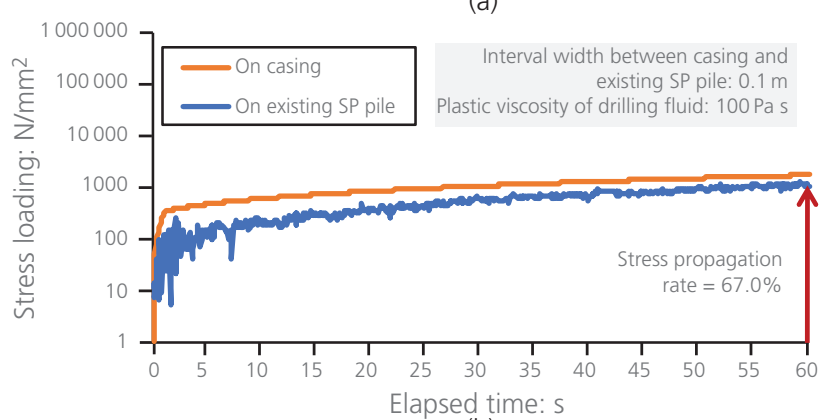

(b)

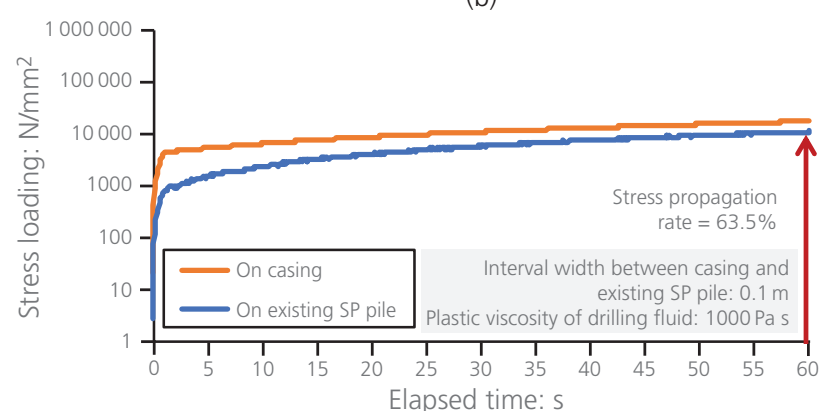

(c)

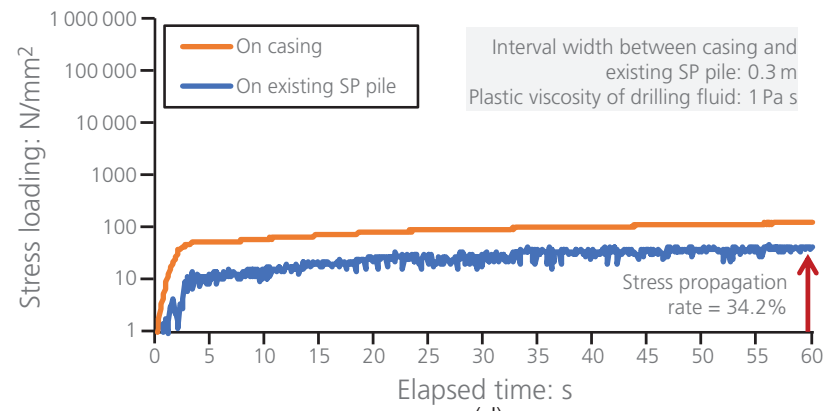

(d)

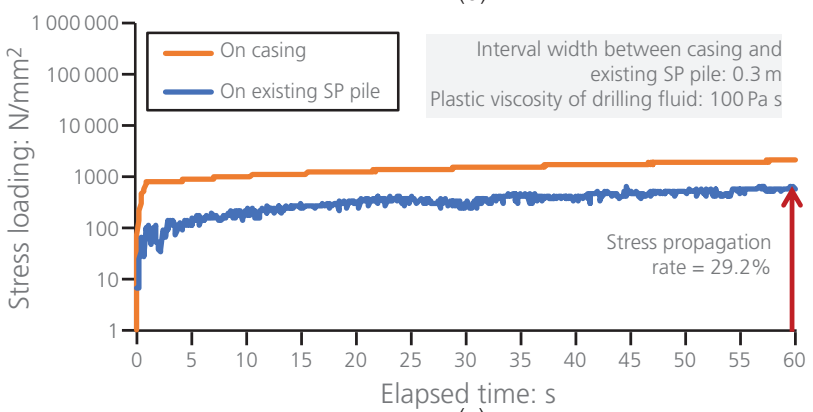

(e)

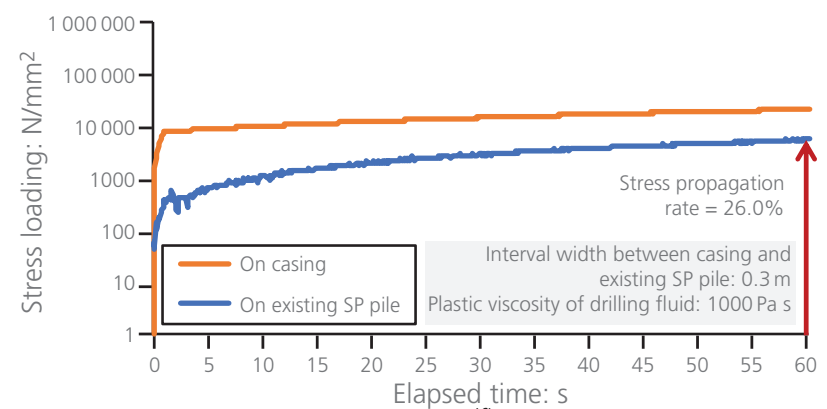

(f)

Figure 12. Stress loaded onto an existing SP pile when the casing is inserted by rotation: (a) Case_SP_0.6_0.1_1;

(b) Case_SP_0.6_0.1_100; (c) Case_SP_0.6_0.1_1000; (d) Case_SP_0.6_0.3_1; (e) Case_SP_0.6_0.3_100; (f) Case_SP_0.6_0.3_1000

$60 \mathrm{~s}$. The figures show time $t$ on the horizontal axis and stress $F$ on the vertical axis, and the percentage is a numerical value representing how much stress is propagated to an existing pile from the value of the stress loaded onto the inside of the casing after $60 \mathrm{~s}$. Considering Figures 11(a)-11(c) and 12(a)-12(c), for the existing PC piles and the existing SP piles, respectively, the magnitude of stress tends to increase proportionally as the value of the plastic viscosity of the drilling fluid increases. However, the propagation rate of the stress from the casing to the existing pile increases as the plastic viscosity of the drilling fluid decreases. This is because the drilling fluid itself has no viscous stress and has almost the same rheological characteristics as water, so the stress from the casing is considered to be propagated quickly. Comparing Figures 11(a)-11(c) and 12(a)-12(c), it is seen that lower values for the plastic viscosity of the drilling fluid are accompanied by greater stress propagation rates, but a smaller effect of the stress on the existing pile. However, higher values for the plastic viscosity of the drilling fluid are accompanied by smaller stress propagation rates from the casing, but a larger effect of the stress on the existing pile. Besides, in Figures 11(a)-11(c) and 12(a)-12(c), the interval width between the casing and the existing pile is approximately $0.1 \mathrm{~m}$, but $100 \%$ of the stress generated from the casing does not become loaded onto the existing pile. Considering cases in which the plastic viscosities of the drilling fluid are the same, the stress propagation when the interval width between the casing and the existing pile is $0.3 \mathrm{~m}$ (see Figures 11(d)-11(f) and 12(d)-12(f)) is smaller than when the interval width is $0.1 \mathrm{~m}$ (see Figures $11(\mathrm{a})-11(\mathrm{c})$ and 12(a)-12(c)): about $50 \%$ or less.

Up to now, engineers have thought that 'the greater the amount of drilling fluid in the interval between the casing and an existing pile, the greater the stress applied to the existing pile, which may lead to the destruction of the existing pile'. In this analysis, the stress applied to the inside of the casing also increases as the amount of drilling fluid increases. However, because of the effect 
Geotechnical Research

Volume 8 Issue 1
Evaluation of effect of insertion of casing

by rotation on existing piles

Inazumi, Tanaka, Komaki and Kuwahara of the interval width on the stress reaching the existing pile, it is considered that the stress becomes smaller when the stress reaches the existing pile.

\section{Evaluation of the maximum stress loaded onto existing piles}

\section{Method for estimating the maximum stress loaded onto} existing piles

The stress loaded on the inside of the casing is approximately constant over time, as shown in Figures 11 and 12. This tendency is considered to continue until the casing has been completely installed by rotation during the removal of an existing pile. Therefore, the amount of change in stress is calculated for 30-60 s in each case in Figures 11 and 12, and the calculated amount of change in stress is added up to the position where the maximum torsional stress is loaded onto the existing pile.

\section{Evaluation of the maximum stress loaded onto existing piles}

Tables 4 and 5 show the safety factors at the locations where the maximum torsional stress is loaded onto existing piles. The safety factors correspond to the value obtained by dividing the maximum torsional stress loading onto existing piles by the allowable shear stress of the existing piles. As the diameter of each pile is $0.3 \mathrm{~m}$ and the number of particles is the same, the torsional stress loaded on the existing pile is assumed to be the same because the interval width between the casing and the existing pile is the same as that of the existing pile. Based on the safety factor in each case (see Tables 5 and 6), the stress loaded onto an existing pile is approximately two to three times different between the interval width of 0.1 and $0.3 \mathrm{~m}$ for both the existing PC and the existing SP piles. When the safety factors are compared for different pile diameters, the safety factor

Table 4. Safety factor against torsional stress loaded onto existing PC piles

\begin{tabular}{|c|c|c|c|c|c|c|}
\hline & Case_PC_0.6_0.1_1 & Case_PC_0.6_0.3_1 & Case_PC_0.6_0.1_100 & Case_PC_0.6_0.3_100 & Case_PC_0.6_0.1_1000 & Case_PC_0.6_0.3_1000 \\
\hline $\begin{array}{l}\text { PC pile } \\
\text { diameter: } \mathrm{m}\end{array}$ & 0.6 & 0.6 & 0.6 & 0.6 & 0.6 & 0.6 \\
\hline Interval width: m & 0.1 & 0.3 & 0.1 & 0.3 & 0.1 & 0.3 \\
\hline $\begin{array}{l}\text { Torsional stress: } \\
\mathrm{N} / \mathrm{mm}^{2}\end{array}$ & $4.83 \times 10^{-3}$ & $2.26 \times 10^{-3}$ & $1.03 \times 10^{-1}$ & $5.09 \times 10^{-2}$ & $9.41 \times 10^{-1}$ & $4.19 \times 10^{-1}$ \\
\hline Torsional angle: & $5.14 \times 10^{-4}$ & $2.41 \times 10^{-4}$ & $1.10 \times 10^{-2}$ & $5.42 \times 10^{-3}$ & $1.00 \times 10^{-1}$ & $4.46 \times 10^{-2}$ \\
\hline \multirow[t]{2}{*}{ Safety factor } & 0.006 & 0.003 & 0.118 & 0.058 & 1.075 & 0.479 \\
\hline & Case_PC_0.3_0.1_1 & Case_PC_0.3_0.3_1 & Case_PC_0.3_0.1_100 & Case_PC_0.3_0.3_100 & Case_PC_0.3_0.1_1000 & Case_PC_0.3_0.3_1000 \\
\hline $\begin{array}{l}\text { PC pile } \\
\text { diameter: } m\end{array}$ & 0.3 & 0.3 & 0.3 & 0.3 & 0.3 & 0.3 \\
\hline Interval width: m & 0.1 & 0.3 & 0.1 & 0.3 & 0.1 & 0.3 \\
\hline $\begin{array}{l}\text { Torsional stress: } \\
\mathrm{N} / \mathrm{mm}^{2}\end{array}$ & $1.93 \times 10^{-2}$ & $9.05 \times 10^{-3}$ & $4.13 \times 10^{-1}$ & $2.03 \times 10^{-1}$ & $3.76 \times 10^{0}$ & $1.68 \times 10^{0}$ \\
\hline Torsional angle: ${ }^{\circ}$ & $4.12 \times 10^{-3}$ & $1.93 \times 10^{-3}$ & $9.80 \times 10^{-2}$ & $4.33 \times 10^{-2}$ & $8.01 \times 10^{-1}$ & $3.57 \times 10^{-1}$ \\
\hline Safety factor & 0.022 & 0.010 & 0.472 & 0.232 & 4.301 & 1.914 \\
\hline
\end{tabular}

Table 5. Safety factor against torsional stress loaded onto existing SP piles

\begin{tabular}{|c|c|c|c|c|c|c|}
\hline & Case_SP_0.6_0.1_1 & Case_SP_0.6_0.3_1 & Case_SP_0.6_0.1_100 & Case_SP_0.6_0.3_100 & Case_SP_0.6_0.1_1000 & Case_SP_0.6_0.3_1000 \\
\hline $\begin{array}{l}\text { SP pile } \\
\quad \text { diameter: } \mathrm{m}\end{array}$ & 0.6 & 0.6 & 0.6 & 0.6 & 0.6 & 0.6 \\
\hline Interval width: m & 0.1 & 0.3 & 0.1 & 0.3 & 0.1 & 0.3 \\
\hline $\begin{array}{l}\text { Torsional stress: } \\
\mathrm{N} / \mathrm{mm}^{2}\end{array}$ & $4.92 \times 10^{-2}$ & $2.04 \times 10^{-2}$ & $8.94 \times 10^{-1}$ & $3.62 \times 10^{-1}$ & $8.20 \times 10^{0}$ & $3.55 \times 10^{0}$ \\
\hline Torsional angle: ${ }^{\circ}$ & $9.31 \times 10^{-4}$ & $3.86 \times 10^{-4}$ & $1.69 \times 10^{-2}$ & $6.85 \times 10^{-3}$ & $1.55 \times 10^{-1}$ & $6.71 \times 10^{-2}$ \\
\hline \multirow[t]{2}{*}{ Safety factor } & 0.001 & 0.000 & 0.010 & 0.004 & 0.091 & 0.039 \\
\hline & Case_SP_0.3_0.1_1 & Case_SP_0.3_0.3_1 & Case_SP_0.3_0.1_100 & Case_SP_0.3_0.3_100 & Case_SP_0.3_0.1_1000 & Case_SP_0.3_0.3_1000 \\
\hline $\begin{array}{l}\text { SP pile } \\
\text { diameter: m }\end{array}$ & 0.3 & 0.3 & 0.3 & 0.3 & 0.3 & 0.3 \\
\hline Interval width: m & 0.1 & 0.3 & 0.1 & 0.3 & 0.1 & 0.3 \\
\hline $\begin{array}{l}\text { Torsional stress: } \\
\mathrm{N} / \mathrm{mm}^{2}\end{array}$ & $1.28 \times 10^{-1}$ & $5.31 \times 10^{-2}$ & $2.33 \times 10^{0}$ & $9.42 \times 10^{-1}$ & $2.14 \times 10^{1}$ & $9.23 \times 10^{0}$ \\
\hline Torsional angle: ${ }^{\circ}$ & $4.57 \times 10^{-3}$ & $1.90 \times 10^{-3}$ & $8.31 \times 10^{-2}$ & $3.36 \times 10^{-2}$ & $7.62 \times 10^{-1}$ & $3.30 \times 10^{-1}$ \\
\hline Safety factor & 0.001 & 0.001 & 0.026 & 0.01 & 0.236 & 0.102 \\
\hline
\end{tabular}


Table 6. Classification of stress loaded onto existing PC piles

\begin{tabular}{|c|c|c|c|c|c|c|}
\hline & $\begin{array}{l}\text { Interval } \\
\text { width: } \mathrm{m}\end{array}$ & $\begin{array}{l}\text { Viscosity term: } \\
\qquad \mathrm{N} / \mathrm{mm}^{2}\end{array}$ & $\begin{array}{l}\text { Pressure term: } \\
\qquad \mathrm{N} / \mathrm{mm}^{2}\end{array}$ & $\begin{array}{l}\text { Surface tension: } \\
\qquad \mathrm{N} / \mathrm{mm}^{2}\end{array}$ & $\begin{array}{l}\text { External force term: } \\
\qquad \mathrm{N} / \mathrm{mm}^{2}\end{array}$ & $\begin{array}{l}\text { Stress loading: } \\
\mathrm{N} / \mathrm{mm}^{2}\end{array}$ \\
\hline $\begin{array}{l}\text { Case_PC_0.6_0.1_1 } \\
\text { Case_PC_0.3_0.1_1 }\end{array}$ & 0.1 & $5.57 \times 10^{1}$ & $3.83 \times 10^{0}$ & $0.00 \times 10^{0}$ & $0.00 \times 10^{0}$ & $5.95 \times 10^{1}$ \\
\hline $\begin{array}{l}\text { Case_PC_0.6_0.3_1 } \\
\text { Case_PC_0.3_0.3_1 }\end{array}$ & 0.3 & $3.67 \times 10^{1}$ & $3.02 \times 10^{0}$ & $0.00 \times 10^{0}$ & $0.00 \times 10^{0}$ & $3.97 \times 10^{1}$ \\
\hline $\begin{array}{l}\text { Case_PC_0.6_0.1_100 } \\
\text { Case_PC_0.3_0.1_100 }\end{array}$ & 0.1 & $1.16 \times 10^{3}$ & $2.46 \times 10^{1}$ & $0.00 \times 10^{0}$ & $0.00 \times 10^{0}$ & $1.19 \times 10^{3}$ \\
\hline $\begin{array}{l}\text { Case_PC_0.6_0.3_100 } \\
\text { Case_PC_0.3_0.3_100 }\end{array}$ & 0.3 & $9.09 \times 10^{2}$ & $3.26 \times 10^{1}$ & $0.00 \times 10^{0}$ & $0.00 \times 10^{0}$ & $9.41 \times 10^{2}$ \\
\hline $\begin{array}{l}\text { Case_PC_0.6_0.1_1000 } \\
\text { Case_PC_0.3_0.1_1000 }\end{array}$ & 0.1 & $1.03 \times 10^{4}$ & $1.20 \times 10^{2}$ & $0.00 \times 10^{0}$ & $0.00 \times 10^{0}$ & $1.04 \times 10^{4}$ \\
\hline $\begin{array}{l}\text { Case_PC_0.6_0.3_1000 } \\
\text { Case_PC_0.3_0.3_1000 }\end{array}$ & 0.3 & $5.54 \times 10^{3}$ & $1.59 \times 10^{2}$ & $0.00 \times 10^{0}$ & $0.00 \times 10^{0}$ & $5.69 \times 10^{3}$ \\
\hline
\end{tabular}

Table 7. Classification of stress loaded onto existing SP piles

$\begin{array}{lcccccc} & \begin{array}{c}\text { Interval } \\ \text { width: } \mathbf{m}\end{array} & \begin{array}{c}\text { Viscosity term: } \\ \mathbf{N} / \mathbf{m m}^{2}\end{array} & \begin{array}{c}\text { Pressure term: } \\ \mathbf{N} / \mathbf{m m}^{2}\end{array} & \begin{array}{c}\text { Surface tension: } \\ \mathbf{N} / \mathbf{m m}^{2}\end{array} & \begin{array}{c}\text { External force term: } \\ \mathbf{N} / \mathbf{m m}^{2}\end{array} & \begin{array}{c}\text { Stress loading: } \\ \mathbf{N} / \mathbf{m m}^{2}\end{array} \\ \begin{array}{l}\text { Case_SP_0.6_0.1_1 } \\ \text { Case_SP_0.3_0.1_1 }\end{array} & 0.1 & 4.26 \times 10^{1} & 2.91 \times 10^{1} & 0.00 \times 10^{0} & 0.00 \times 10^{0} & 7.17 \times 10^{1} \\ \begin{array}{l}\text { Case_SP_0.6_0.3_1 } \\ \text { Case_SP_0.3_0.3_1 }\end{array} & 0.3 & 2.29 \times 10^{1} & 1.74 \times 10^{1} & 0.00 \times 10^{0} & 0.00 \times 10^{0} & 4.03 \times 10^{1} \\ \begin{array}{l}\text { Case_SP_0.6_0.1_100 } \\ \text { Case_SP_0.3_0.1_100 }\end{array} & 0.1 & 1.10 \times 10^{3} & 5.72 \times 10^{1} & 0.00 \times 10^{0} & 0.00 \times 10^{0} & 1.15 \times 10^{3} \\ \begin{array}{l}\text { Case_SP_0.6_0.3_100 } \\ \text { Case_SP_0.3_0.3_100 }\end{array} & 0.3 & 5.27 \times 10^{2} & 8.06 \times 10^{1} & 0.00 \times 10^{0} & 0.00 \times 10^{0} & 6.07 \times 10^{2} \\ \begin{array}{l}\text { Case_SP_0.6_0.1_1000 } \\ \text { Case_SP_0.3_0.1_1000 }\end{array} & 0.1 & 1.04 \times 10^{4} & 4.00 \times 10^{2} & 0.00 \times 10^{0} & 0.00 \times 10^{0} & 1.08 \times 10^{4} \\ \text { Case_SP_0.6_0.3_1000 } & 0.3 & 5.53 \times 10^{3} & 4.68 \times 10^{1} & 0.00 \times 10^{0} & 0.00 \times 10^{0} & 5.57 \times 10^{3} \\ \text { Case_SP_0.3_0.3_1000 } & & & & & \end{array}$

changes approximately four times, the torsional angle changes approximately five times and the amount of change tends to increase as the plastic viscosity of the drilling fluid increases.

\section{Mechanism of stress loaded onto existing piles by} inserting the casing in the ground by rotation

The classification of the stress loaded onto existing piles is shown in Tables 6 and 7. In the MPS-CAE analysis, stress loading is defined as the sum of the viscosity term, pressure term, surface tension term and external stress term. From Tables 6 and 7, the viscosity term and pressure term are the stresses that are mainly loaded onto existing piles. As a mechanism of the stress loaded onto the existing piles at an on-site location, it is thought that when the casing is inserted into the ground by rotation, pressure from the drilling fluid is generated in the direction of the existing pile, and the insertion of the casing by rotation causes frictional stress at the boundary between the existing pile and the drilling fluid and generates torsional stress (see Figure 13). When summarised comprehensively, based on Tables 6 and 7, in the case of both existing PC pile and SP pile, when the value of the plastic viscosity of the drilling fluid is $1000 \mathrm{~Pa} \mathrm{~s}$ or less and the casing diameter is $0.1 \mathrm{~m}$ larger than the existing pile, an existing pile with a diameter of less than $30 \mathrm{~cm}$ is unlikely to break due to the insertion of the casing by rotation.

\section{Conclusions}

This study used MPS-CAE analysis to evaluate the effect of the stress loaded onto existing piles due to the insertion of a steel 
Geotechnical Research

Volume 8 Issue 1
Evaluation of effect of insertion of casing

by rotation on existing piles

Inazumi, Tanaka, Komaki and Kuwahara

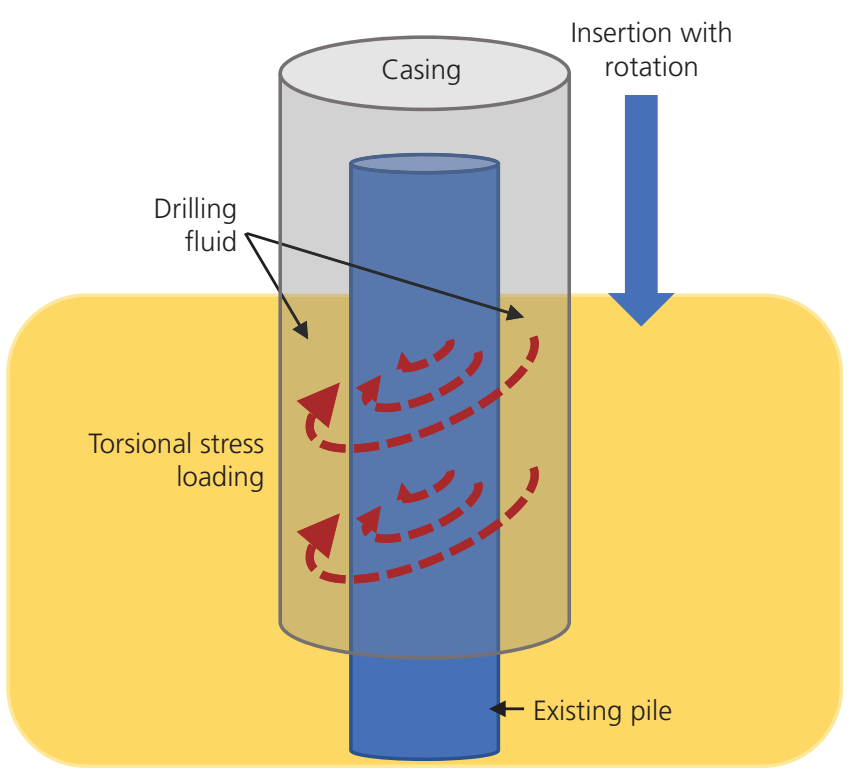

Figure 13. Mechanism revealed by MPS-CAE analysis on torsional stress loaded onto an existing pile

casing by rotation into the ground and to elucidate the generation mechanism in the removal work, which is an issue at on-site locations.

The results obtained from the analysis are summarised as follows.

- Up to now, engineers have thought that 'the greater the amount of drilling fluid in the interval between the casing and an existing pile, the greater the stress applied to the existing pile, which may lead to the destruction of the existing pile'. In this analysis, the stress applied to the inside of the casing is also seen to increase as the amount of drilling fluid increases. However, because of the effect of the interval width on the stress reaching the existing pile, it is thought that the stress becomes smaller when the stress reaches the existing pile.

- As a mechanism of the stress loaded onto an existing pile at an on-site location, it is considered that when the casing is inserted into the ground by rotation, pressure of the drilling fluid is generated in the direction of the existing pile, and the insertion of the casing by rotation causes frictional stress at the boundary between the existing pile and the drilling fluid and generates torsional stress.

- In the case of both existing PC pile and SP pile, when the value of the plastic viscosity of the drilling fluid is $1000 \mathrm{~Pa} \mathrm{~s}$ or less and the casing diameter is $0.1 \mathrm{~m}$ larger than the existing pile, an existing pile with a diameter of less than $30 \mathrm{~cm}$ is unlikely to break due to the insertion of the casing by rotation.

As future work, it will be necessary to use on-site data for the value of the plastic viscosity of the drilling fluid and to evaluate the stress loaded onto existing piles when the insertion and rotation velocities of the casing are changed. In addition, standards must be set to prevent existing piles from being destroyed during the removal work.

\section{REFERENCES}

Chang KH (2014) Product Design Modeling Using CAD/CAE. Academic Press, Amsterdam, the Netherlands.

Hattori M (2015) An attempt to apply mathematical foundation of Moving Particle Simulation to the MPS software 'Particleworks'. Proceedings of the 2015 Symposium on the Educational Application of Information Technology, vol. 9, pp. 59-62.

Inazumi S, Namikawa T, Kuwahara S and Hamaguchi S (2017) Influence of pulling out existing piles on the surrounding ground. International Journal of GEOMATE: Geotechnique, Construction Materials and Environment 13(35): 16-21, https://doi.org/10.21660/2017.35.6544.

Inazumi S, Komaki T, Nakanishi Y, Hashida H and Suzuki M (2018) Qualities evaluation on high pressure jet mixing ground improvement methods by distinct element method (DEM). Proceedings of the 13th National Symposium on Ground Improvement, Tokyo, Japan, pp. 211-216.

Inazumi S, Kuwahara S, Jotisankasa A and Chaiprakaikeow S (2020a) Construction method for pulling out existing piles and influence of pulling-out holes on the surrounding ground. Geotechnical and Geological Engineering 38(6): 6107-6123, https://doi.org/10.1007/ s10706-020-01418-y.

Inazumi S, Kuwahara S, Jotisankasa A and Chaiprakaikeow S (2020b) MPS-CAE simulation on dynamic interaction between steel casing and existing pile when pulling out existing piles. International Journal of GEOMATE: Geotechnique, Construction Materials and Environment 18(70): 68-73, https://doi.org/10.21660/2020.70.9166.

Inazumi S, Kuwahara S, Shimada Y et al. (2020c) Visualization and performance evaluation of existing pile pulling method with pile tip chucking by MPS-CAE. Japanese Geotechnical Journal 15(2): 383-393.

Inazumi S, Kuwahara S, Jotisankasa A and Chaiprakaikeow S (2021) Improvement mechanism of sodium carbonate on traditional composite filler. Proceedings of the Institution of Civil Engineers Ground Improvement, https://doi.org/10.1680/jgrim.19.00014.

JSA (Japanese Standards Association) (2019) JIS A 5525:2019: Steel pipe piles. JSA, Tokyo, Japan.

Kuwahara S and Inazumi S (2019) Settlement of surrounding grounds due to existence of pile pulling-out holes. International Journal of GEOMATE: Geotechnique, Construction Materials and Environment 16(54): 81-85, https://doi.org/10.21660/2019.54.8132.

Kuwahara S, Hamaguchi S, Shimada Y and Inazumi S (2019) Construction theories and examples for method of powerfully chucking the tip of existing pile at removal of existing piles. Japanese Geotechnical Journal 14(1): 69-76.

Kuwahara S, Inazumi S, Jotisankasa A and Chaiprakaikeow S (2020) Influence of the condition of pullout holes on the surrounding ground. International Journal of Geo-engineering 11(1): article 10, https://doi. org/10.1186/s40703-020-00117-0.

Nakamura $\mathrm{H}$ and Nakamura T (2000) Casing design - our effort to improve it. Journal of the Japanese Association for Petroleum Technology 65(5): 393-402.

Nishino F (1987) Steel Structures Series 3A, Design Code for Steel Structures - Part A; Structures in General. Japan Society of Civil Engineers, Tokyo, Japan.

Nixon JF and McRoberts EC (1976) A design approach for pile foundations in permafrost. Canadian Geotechnical Journal 13(1): 40-57, https://doi.org/10.1139/t76-005.

Pan Z, Wang X, Teng R and Cao X (2016) Computer-aided design-whileengineering technology in top-down modeling of mechanical product. Computers in Industry 75: 151-161, https://doi.org/10.1016/j.compind. 2015.05.004. 
Geotechnical Research

Volume 8 Issue 1
Evaluation of effect of insertion of casing

by rotation on existing piles

Inazumi, Tanaka, Komaki and Kuwahara
Rahman SS and Chilingarian GV (1995) Casing Design: Theory and Practice. Elsevier Science, Amsterdam, the Netherlands.

Shakibaeini A and Jin YC (2012) MPS mesh-free particle method for multiphase flows. Computer Methods in Applied Mechanics and Engineering 229-232: 13-26, https://doi.org/10.1016/j.cma.2012. 03.013
Tanaka M, Cardoso R and Bahai H (2018) Multi-resolution MPS method. Journal of Computational Physics 359: 106-136, https://doi.org/10. 1016/j.jcp.2017.12.042.

Yang P, Zang M and Zeng H (2020) DEM-FEM simulation of tire-sand interaction based on improved contact model. Computational Particle Mechanics 7(4): 629-643, https://doi.org/10.1007/s40571-019-00293-6.

\section{How can you contribute?}

To discuss this paper, please submit up to 500 words to the editor at journals@ice.org.uk. Your contribution will be forwarded to the author(s) for a reply and, if considered appropriate by the editorial board, it will be published as a discussion in a future issue of the journal. 